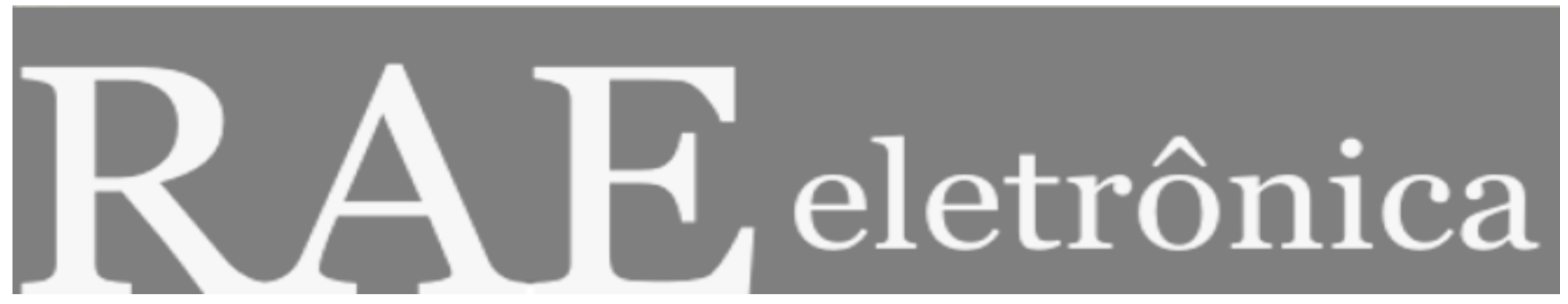

\title{
ASPECTOS COMPORTAMENTAIS ASSOCIADOS Às REAÇÕES DO MERCADO DE CAPITAIS
}

Por:

\section{Herbert Kimura}

RAE-eletrônica, Volume 2, Número 1, jan-jun/2003.

http://www.rae.com.br/eletronica/index.cfm?FuseAction $=$ Artigo $\& I D=1880 \&$ Secao $=2{ }^{\circ} \mathrm{PWC} \&$ Volume $=2 \&$ Numero $=1 \&$ Ano $=2003$

CCopyright, 2002, RAE-eletrônica. Todos os direitos, inclusive de tradução, são reservados. É permitido citar parte de artigos sem autorização prévia desde que seja identificada a fonte. A reprodução total de artigos é proibida. Os artigos só devem ser usados para uso pessoal e nãocomercial. Em caso de dúvidas, consulte a redação: redacao@rae.com.br.

A RAE-eletrônica é a revista on-line da FGV-EAESP, totalmente aberta e criada com o objetivo de agilizar a veiculação de trabalhos inéditos. Lançada em janeiro de 2002, com perfil acadêmico, é dedicada a professores, pesquisadores e estudantes. Para mais informações consulte o site www.rae.com.br/eletronica.

\section{RAE-eletrônica}

ISSN 1676-5648

(C)2002 Editora: Fundação Getulio Vargas - Escola de Administração

de Empresas de São Paulo.

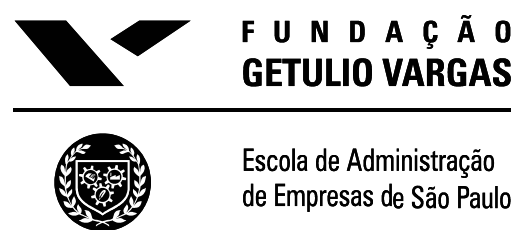




\title{
ASPECTOS COMPORTAMENTAIS ASSOCIADOS ÀS REAÇÕES DO MERCADO DE CAPITAIS
}

\section{Herbert Kimura}

Doutorando em Administração de Empresas - FGV-EAESP

Email: herbert.kimura@ascent.com.br

Endereço: Av. Nove de Julho, 2029 - Bela Vista - São Paulo, SP

Interesses de pesquisa: Gestão de riscos, Modelos financeiros, Avaliação de derivativos, Processos de tomada de decisão.

\section{RESUMO}

Neste artigo, serão apresentados os fundamentos, as evidências empíricas e os modelos alternativos de finanças comportamentais que buscam identificar reações dos mercados potencialmente influenciadas pela psicologia do investidor. Será implementada uma metodologia de avaliação quantitativa de reações anormais de preço para investigação da viabilidade de estratégias contrárias e de momento no caso específico de ativos do mercado de capitais brasileiro. Os resultados sugerem, quando não são considerados ajustes pelo nível de risco, a existência da influência de aspectos comportamentais no mercado. Esta influência está refletida na rentabilidade superior das estratégias de momento em horizontes de treze a quinze semanas após os investimentos, ao nível de significância de 5\%. Porém, quando se realiza ajuste de retornos pelo risco sistemático, os resultados não permitem rejeitar a hipótese de eficiência da carteira de mercado e, desta forma, estratégias contrárias ou de momento não possibilitam ganhos estatisticamente significantes.

\begin{abstract}
In this article, it will be presented the basics, empiric evidences and alternative models of behavioral finance that attempt to identify market reactions potentially influenced by the investor's psychology. It will be implemented a quantitative methodology of evaluation of abnormal price reactions, in order to investigate the viability of contrarian and momentum strategies, in the specific case of assets from the Brazilian stock market. When it is not considered adjustments by the risk level, results suggest the existence of influence from investor's behavior in the market. Such influence is reflected in the higher profitability, at the 5\% significance level, of the momentum strategies between the thirteen to fifteen week's horizons after investments. But when it is performed the adjustment of returns by systematic risk, results do not allow rejecting the hypothesis of efficiency of the market portfolio, and thus, the contrarian or momentum strategies do not allow extraordinary gains.
\end{abstract}

\section{PALAVRAS-CHAVE}

Finanças comportamentais, Reações de mercado, Anomalias de mercado, Hipótese de mercados eficientes, Comportamento do investidor

\section{KEY-WORDS}

Behavioral finance, Market reactions, Market anomalies, Efficient market hypothesis, Investor behavior 


\section{INTRODUÇÃO}

\subsection{Conceitos iniciais}

As finanças comportamentais representam um novo ramo na teoria financeira, que busca incorporar os aspectos psicológicos dos indivíduos no processo de avaliação e precificação de ativos financeiros. Por apresentar uma visão multidisciplinar, envolvendo modelos financeiros tradicionais, métodos quantitativos, economia e psicologia, as finanças comportamentais surgem como uma das mais importantes e surpreendentes inovações na teoria de finanças nos últimos anos.

Desafiando o paradigma imposto pela hipótese de mercados eficientes, as finanças comportamentais consideram que os investidores podem agir de maneira não-racional impactando consistemente o comportamento do mercado. Assim, os defensores das finanças comportamentais advogam a possibilidade de ganhos extraordinários decorrentes de distorções previsíveis nos preços dos ativos financeiros. Para exemplificar a crescente inserção das finanças comportamentais na realidade financeira, pelo menos setenta bilhões de dólares de recursos já são geridos levando-se em consideração técnicas baseadas na psicologia dos investidores.

Neste artigo, serão apresentados os fundamentos de finanças comportamentais e as principais evidências empíricas associadas às reações do mercado de capitais, enfatizando as anomalias em relação aos resultados esperados sob premissas da hipótese de eficiência de mercado. Serão também discutidos os modelos alternativos de finanças comportamentais que foram desenvolvidos para explicar as reações dos mercados influenciadas pela psicologia do investidor. Finalmente, será implementada uma metodologia para avaliação empírica de reações anormais de preço, investigando-se a viabilidade de estratégias operacionais classificadas como estratégias contrárias e estratégias de momento para o caso específico de ativos do mercado brasileiro.

\subsection{Aplicações de finanças comportamentais}

Estudos empíricos têm revelado que os agentes financeiros apresentam atitudes viesadas decorrentes da forma de estruturação de problemas e resultados, violando premissas da teoria moderna de finanças. Neste contexto, Shefrin (2000) estabelece que as finanças comportamentais estão direcionadas para o estudo das seguintes questões:

- Os erros de decisão financeira ocorrem porque investidores confiam demasiadamente em regras ou modelos gerais?

- Os investidores são influenciados pela forma com que informações e conteúdos são expostos ou estruturados?

- Os preços de equilíbrio definidos pelo mercado são afetados por erros e estruturas mentais?

Assim, em seu processo de investigação, as finanças comportamentais têm importante aplicação prática em diversas áreas (Burr, 1997):

- Investimentos: o entendimento do processo psicológico que motiva investimentos, principalmente no que concerne à estruturação de alternativas, pode possibilitar a construção de um modelo mais adequado de tomada de decisão financeira. 
- Análise de movimentos de mercado: os agentes financeiros podem apresentar diversos problemas e vieses na tomada de decisão, como, por exemplo, sobre-valorização de fatos mais recentes e, portanto, é importante a análise dos impactos do comportamento humano na formação de preços.

- Explicação de anomalias de mercado: a análise das percepções, do processo de formação de opiniões e de construção da memória dos indivíduos pode auxiliar no entendimento da formação de bolhas especulativas, por exemplo.

- Relacionamento com clientes: para consultores financeiros, o estudo do comportamento dos indivíduos, como, por exemplo, vieses de percepção, nível de arrependimento ou atitudes perante diferentes estruturações, torna-se fundamental no processo de aconselhamento de investimentos.

- Desenvolvimento de produtos financeiros: a aversão ou propensão a risco, a perdas ou a ambigüidade pode se tornar fator crítico para o sucesso de novos produtos financeiros.

- Contratação de administradores de recursos: gestores de recursos financeiros devem ter habilidades técnicas e psicológicas adequadas para evitar armadilhas de tomada de decisão, como, por exemplo, excesso de confiança.

\subsection{Aspectos comportamentais}

Apesar de a hipótese de mercados eficientes supor a predominância de investidores racionais, o comportamento humano é influenciado por diversos aspectos psicológicos, que podem distorcer o processo racional de tomada de decisão. A seguir, alguns vieses de decisão são discutidos, justificando a relevância das finanças comportamentais.

\section{a) Dissonância cognitiva}

As atitudes dos investidores podem ser influenciadas pelas tentativas de diminuição de sua dissonância cognitiva, uma vez que existe uma motivação natural para a redução de conflitos internos. Por exemplo, suponha um investidor que comprou uma determinada ação devido a uma expectativa de alta dos preços. No caso de queda acentuada do preço da ação, talvez a grande perda seja encarada como um resultado pouco relevante. Este comportamento é uma forma de diminuição da dissonância cognitiva, que pode surgir como uma defesa psicológica para justificar a aquisição da ação e diminuir a importância da perda causada pelo investimento. Em termos práticos, este fato pode estar associado à evidência empírica de os indivíduos postergarem a realização de prejuízos.

\section{b) Heurística da representatividade}

A representatividade é uma heurística que se refere ao julgamento baseado em estereótipos (Shefrin, 2000). No caso de investimentos, a heurística da representatividade pode influenciar a percepção dos investidores sobre o potencial de valorização de uma ação. Investidores podem avaliar positivamente o potencial de uma ação específica simplesmente em função de terem formado uma opinião estereotipada sobre a empresa. Esta visão pode ser conseqüência da simpatia pela empresa, do desempenho passado da empresa ou de informações obtidas através de outros investidores ou meios de comunicação. 


\section{c) Excesso de confiança}

Diversas pesquisas têm demonstrado que os indivíduos apresentam excesso de confiança em suas habilidades. Segundo Plous (1993), nenhum outro problema de julgamento e tomada de decisão tem maior poder de catástrofe do que o excesso de confiança. No processo de tomada de decisão de investimento, o excesso de confiança pode ter diversas conseqüências. Primeiramente, pode levar o investidor a crer que possui vantagens comparativas na análise e avaliação de ativos em relação ao mercado, mantendo posições perdedoras. Além disso, o excesso de confiança pode levar a demasiada exposição em determinados ativos, tendo em vista a crença viesada do investidor em que seu posicionamento no ativo conduzirá a ganhos futuros consideráveis. Neste contexto, pode haver uma diversificação de investimentos inadequada, devido à concentração da carteira em determinados ativos.

\section{d) Ancoragem e conservadorismo}

Edwards (1964) propõe um problema baseado em probabilidades para demonstrar que os indivíduos têm um valor de referência que ancora suas percepções levando-os a estabelecer estimativas conservadoras. Shefrin (2000) afirma que a deficiência de o indivíduo em analisar informação adicional é análoga à deficiência que os analistas financeiros apresentam quando fazem novas projeções sobre lucros futuros de uma empresa, em função do surgimento de nova informação relevante. Assim, os analistas não revisam suficientemente suas estimativas para refletir novas informações.

\section{FINANÇAS COMPORTAMENTAIS}

\subsection{Conceitos iniciais}

Por desafiar os conceitos tradicionais impostos pela teoria moderna de finanças, as finanças comportamentais representam o trabalho teórico mais interessante em investimentos surgido na ciência financeira nos últimos anos (Burr, 1997). Para Shleifer (2000), as finanças comportamentais representam o estudo do potencial de falha humana em mercados competitivos, abordando os impactos em variáveis financeiras quando diversos tipos de investidores, tanto racionais quanto irracionais, interagem entre si.

As origens das finanças comportamentais estão associadas às aplicações das descobertas da psicologia na teoria econômica. Os estudos pioneiros de Kahneman e Tversky (1979) sobre erros de heurística e as pesquisas comportamentais de Slovic (1972) a respeito de problemas de percepção de risco abriram caminho para a avaliação da influência dos aspectos psicológicos no processo de tomada de decisão dos investidores.

Por muito tempo, porém, o estudo do comportamento aplicado às finanças angariou pouco interesse de pesquisadores, uma vez que a teoria moderna de finanças, fundamentada na hipótese de mercados eficientes, reinava absoluta no meio acadêmico, e o modelo de precificação de ativos, baseado na remuneração do risco sistemático, parecia explicar adequamente as evidências empíricas dos mercados financeiros. 
Com o aprofundamento das pesquisas e com o aprimoramento das técnicas de avaliação quantitativa em finanças ocorridos principalmente após 1980, diversos acadêmicos começaram a identificar indícios de que o comportamento real do mercado distanciava-se dos resultados esperados pela hipótese de mercados eficientes.

Enquanto a hipótese de eficiência de mercado estabelece que agentes financeiros utilizam a regra de Bayes para estimarem valores futuros de forma não viesada, a teoria proposta por Kahneman e Tversky (1979) supõe que os investidores tendem a adotar heurísticas bem como processos mentais viesados, que violam modelos estatísticos básicos. Desta maneira, decisões baseadas em estereótipos, excesso de confiança, conservadorismo e aversão à ambigüidade podem levar a uma flutuação de preços incompatível com a hipótese de mercados eficientes.

Shleifer (2000) estabelece que as finanças comportamentais fundamentam-se em dois tipos de argumentos: limitação da arbitragem no mercado financeiro e atitudes mentais dos investidores. Desta forma, uma vez que as possibilidades de arbitragem não são totalmente eliminadas devido à estrutura do mercado, como por exemplo, a inexistência de ativos substitutos perfeitos para sintetizar posições e a demanda por ativos financeiros estabelecida a partir de crenças e avaliações viesadas, prováveis distúrbios no mercado podem causar desequilíbrios persistentes de preço na forma de sobre-reação ou sub-reação de mercado.

\subsection{Sobre-reação}

A sobre-reação de mercado surge quando variáveis financeiras, como por exemplo, preços e volatilidades, distanciam-se excessivamente de seus valores intrínsecos. Assim, a heurística da representatividade pode estar associada à sobre-reação. Ou seja, as notícias de desempenho passado bom ou ruim de uma empresa podem influenciar o processo de tomada de decisão, causando, respectivamente, euforia ou desânimo excessivo e provocando uma sobre-reação do mercado.

A descoberta de sobre-reações tem implicações práticas, pois justifica a adoção de estratégias de investimentos classificadas como estratégias contrárias. Estas estratégias de compra de ativos com desempenho passado abaixo da média e de venda de ativos com desempenho passado acima da média, fundamentam-se na suposição de que os investidores depreciam ou valorizam exageradamente ações com histórico ruim ou bom, respectivamente. Assim, existe uma sobre-reação de preços que pode ser explorada, pois, se ao longo do tempo os preços se ajustarem aos seus valores intrínsecos, a estratégia contrária pode conduzir a retornos acima da média do mercado.

A sobre-reação relacionada ao índice entre preço e lucro por ação (P/L) é talvez uma das anomalias mais estudadas pelos acadêmicos. Basu (1977) identifica que ações com P/L baixo tendem a obter retornos ajustados pelo risco superiores a ações com $\mathrm{P} / \mathrm{L}$ alto. Esta reação excessiva pode sobreviver ao processo de arbitragem, pois o número de investidores racionais pode ser insuficiente para garantir um equilíbrio baseado na hipótese de mercados eficientes.

De Bondt e Thaler (1985) observam empiricamente, para o contexto dos Estados Unidos, que carteiras formadas pelas trinta e cinco ações de pior desempenho em anos anteriores tiveram, em média, três anos depois, cerca de $20 \%$ de desempenho superior ao da carteira representativa do mercado. Mun, Vasconcellos e Kish (2000) avaliam a estratégia contrária utilizando técnicas 
não-paramétricas e sugerem que a estratégia contrária conduz a ganhos significativos no curto e médio prazo, para o caso americano. Para o caso do mercado canadense, a estratégia contrária possibilita resultados positivos consistentes apenas para horizontes de tempo de médio prazo.

Embora diversos estudos tenham sugerido a existência de sobre-reações, o tema é ainda muito controverso. Zarowin (1990) argumenta que se os resultados obtidos por De Bondt e Thaler (1985) fossem corrigidos pelo efeito janeiro e pelo tamanho da empresa, as evidências de sobre-reação não se verificariam. Para Ball e Kothari (1989), o desempenho extraordinário das estratégias contrárias seria reflexo da alteração no nível de risco sistemático das ações e não de uma potencial sobre-reação de preços.

\subsection{Sub-reação}

Levy (1967), através de estudos de análise técnica, identificou a possibilidade de ganhos extraordinários devido à sub-reação de mercado. A partir da obtenção de ganhos extraordinários com estratégias baseadas na compra de ações com preços substancialmente maiores que o preço médio das últimas vinte e sete semanas, observou-se que a alta de curto prazo de um ativo financeiro não incorporava todo o potencial de crescimento de valor, evidenciando uma subreação. Ou seja, a alta recente do papel seria indicador de uma alta futura consistente.

O estudo da existência de sub-reação também é relevante para a prática financeira, pois possíveis sub-reações podem induzir o estabelecimento de estratégias de momento, ou seja, estratégias onde ativos com desempenho passado acima da média ou com características boas são comprados e ativos com desempenho passado abaixo da média ou com características ruins são vendidos.

A sub-reação pode ser decorrente de um fator psicológico definido por Edwards (1964) como conservadorismo. Assim, investidores podem demorar para incorporar informações relevantes no processo de decisão, causando uma lentidão nos ajustes de preço, principalmente quando os sinais do mercado diferem das percepções e avaliações particulares dos indivíduos.

Jegadeesh e Titman (1993) identificam que estratégias de momento propiciam, em um horizonte de tempo de três a doze meses, ganhos extraordinários. Assim, os autores documentam que os retornos médios das ações estão relacionados positivamente com desempenho passado. Considerando a sub-reação sob o ponto de vista de disponibilização de informação, Chan, Jegadeesh e Lakonishok (1996) defendem que o mercado sub-reage tanto à informação inicialmente privada, quanto à informação pública disponibilizada simultaneamente a todos os investidores.

Assim como no caso da sobre-reação, diferentes estudos apresentam resultados contraditórios. Para Conrad e Kaul (1998), a verificação histórica de ganhos com estratégias de momento pode ser influenciada pelo processo de cálculo de retornos. Desta maneira, a aparente sub-reação do mercado pode ser resultado de vieses metodológicos e não de aspectos comportamentais dos investidores. Adicionalmente, para Jegadeesh e Titman (1993), diversas análises que suportam a inexistência de sub-reação não são publicadas simplesmente por terem baixo apelo científico. 


\subsection{Modelos de finanças comportamentais}

As finanças comportamentais têm como fundamento a teoria de prospecto, na qual as probabilidades são substituídas por pesos de decisão e os valores são atribuídos aos ganhos e às perdas ao invés de serem relacionados aos resultados finais. A função de valor é côncava no domínio dos ganhos e convexa no domínio das perdas e geralmente mais inclinada nas perdas do que nos ganhos. Os pesos de decisão são mais baixos do que as probabilidades, exceto no intervalo correspondente às situações cuja probabilidade de ocorrência é baixa (Kahneman e Tversky, 1979). Assim, a teoria de prospecto permite identificar comportamentos diferenciados frente às perdas e aos ganhos, como por exemplo, a disposição do indivíduo em aumentar sua exposição a riscos visando recuperar perdas passadas e a tendência do investidor em reverter posições prematuramente para realizar lucros.

Nos últimos anos, modelos teóricos baseados em comportamento dos investidores têm sido propostos para explicar possíveis sobre-reações ou sub-reações de mercado. Em geral, as evidências mostram a existência de uma tendência de sub-reação de curto prazo e de uma tendência de os preços sobre-reagirem no longo prazo.

\section{a) Modelo de Barberis, Shleifer e Vishny}

Barberis, Shleifer e Vishny (1998) propõem um modelo financeiro motivados pela evidência da existência de dois vieses de julgamento baseados na psicologia cognitiva: o viés da representatividade e o conservadorismo. Assim, segundo Kanheman e Tversky (1979), a decisão baseada em estereótipos pode induzir maior ponderação ao comportamento recente e pouca atenção às propriedades da população que gera os dados. O conservadorismo, por sua vez, acarreta lenta atualização de modelos em função de novas evidências (Edwards, 1964). Desta forma, as sobre-reações ou sub-reações de mercado podem ser decorrentes dos vieses de julgamento aos quais os investidores estão expostos.

Barberis, Shleifer e Vishny (1998) estabelecem que os lucros das empresas seguem um passeio aleatório, porém os investidores percebem a existência de duas regras de formação distintas de lucros, com probabilidades diferentes. Para os investidores, a regra de formação de lucros mais provável envolve reversão à média. Neste caso, as ações tendem a apresentar um comportamento de sub-reação, uma vez que os investidores, de maneira errada, pensam que as alterações recentes nos lucros são temporárias. Outro possível regime de lucros, com menor probabilidade estimada de ocorrência, refere-se à existência de uma tendência no comportamento dos lucros. Após algumas sucessivas alterações de lucros com mesmo sinal (variações positivas ou variações negativas consecutivas), os investidores se convencem de que o regime associado à tendência dos lucros está em vigor e, incorretamente, extrapolam a tendência, ocasionando uma sobre-reação do preço.

\section{b) Modelo de Daniel, Hirshleifer e Subramanyam}

Para Daniel, Hirshleifer e Subramanyam (1998), no mercado existem os investidores informados e os investidores não-informados. Os investidores sem informação não apresentam vieses de julgamento. Porém os investidores informados estão sujeitos a dois vieses: o excesso de confiança e a sobre-valorização de suas próprias percepções. 
O excesso de confiança leva os investidores a exagerarem a precisão de suas análises particulares sobre o valor de uma empresa. Os investidores atribuem menor ponderação às análises ou avaliações disponíveis publicamente, especialmente quando os sinais públicos e suas avaliações particulares são contraditórios. Assim, a sobrevalorização da informação privada e sub-valorização da informação pública tendem a produzir momento ou sub-reação no curto prazo e a reversão ou sobre-reação no longo prazo, quando a informação pública tende a superar os vieses comportamentais.

\section{c) Modelo de Hong e Stein}

Hong e Stein (1999) estabelecem que o fenômeno de precificação de ativos é inerente às interações entre agentes heterogêneos não completamente racionais: os expectadores de notícias e os operadores de momento. Os expectadores de notícias fazem estimativas que são condicionadas apenas a opiniões particulares que formam sobre fundamentos futuros, ignorando a informação sobre o histórico de preços passados. Já os operadores de momento condicionam suas análises apenas em medidas simples de preços passados e não observam notícias sobre fundamentos.

No modelo, supõe-se inicialmente um mercado onde apenas os expectadores de notícia atuam e onde pode haver uma certa sub-reação, pois a informação é transmitida com defasagem e, portanto, parcialmente incorporada nos preços no instante em que é revelada ao mercado, levando à sub-reação. Quando o grupo de operadores de momento é incluído neste mercado, procurará obter resultados em função da existência da sub-reação. Porém, se estes agentes realizam estratégias baseados na observação de preços passados, tenderão a extrapolar os preços de mercado além de seus valores intrínsecos, criando momento excessivo que inevitavelmente conduz à sobre-reação. Assim, pelo modelo de Hong e Stein (1999), a existência da sub-reação representa a origem da sobre-reação.

\section{EVIDÊNCIAS EMPÍRICAS PARA O MERCADO BRASILEIRO}

\subsection{Metodologia}

A metodologia para avaliação de reação de preços a ser realizada baseia-se na identificação da diferença entre médias de excessos de retornos acumulados a partir do estabelecimento de uma estratégia contrária de operações no mercado, conforme estudos de De Bondt e Thaler (1985). Assim, são comprados os ativos de pior desempenho passado e vendidos a descoberto os ativos de melhor desempenho passado. Os excessos de retorno, sem ajuste pelo risco, em um determinado período são medidos subtraindo-se do retorno do ativo o retorno de uma carteira de referência que represente o mercado. Quando se realiza ajuste pelo risco, os excessos de retorno são medidos através da diferença entre o retorno do ativo e o retorno esperado, calculado através do CAPM, de um ativo de mesmo risco sistemático.

Os ativos são ranqueados a partir dos excessos de retornos acumulados durante um determinado número de períodos passados. A partir deste resultado, são escolhidos os ativos que compõem as carteiras vencedoras e perdedoras: as ações que apresentarem os maiores excessos de retornos acumulados farão parte das carteiras vencedoras e as ações que apresentarem os menores excessos de retornos acumulados farão parte das carteiras perdedoras. A cada período, os ativos são ranqueados conforme seus excessos de retornos acumulados. 
Para as carteiras vencedoras, é obtido o excesso de retornos acumulados, até um determinado período, através da média aritmética dos excessos de retornos acumulados dos ativos que tiveram melhor desempenho passado. De modo análogo, para as carteiras perdedoras, o excesso de retornos acumulados é calculado utilizando-se a média dos excessos de retorno dos ativos de pior desempenho passado.

Para a determinação da existência de sobre-reação, realiza-se um teste estatístico de diferença de médias. Assim, a hipótese nula a ser testada é $H_{0}: A C A R_{P, t}-A C A R_{V, t}=0$ contra a hipótese alternativa $H_{A}: A C A R_{P, t}-A C A R_{V, t}>0$, onde $A C A R_{P, t}$ representa o excesso de retorno médio acumulado até o período $t$ da carteira perdedora e $A C A R_{V, t}$ representa o excesso de retorno médio acumulado até o período $\mathrm{t}$ da carteira vencedora. Obviamente, a metodologia também permite testar a existência de sub-reação através da análise da hipótese alternativa $\mathrm{H}_{\mathrm{A}}$ : $\mathrm{ACAR}_{\mathrm{V}, \mathrm{t}}-\mathrm{ACAR}_{\mathrm{P}, \mathrm{t}}>0$.

Portanto, os resultados da aplicação da metodologia apontam para uma sobre-reação de preços se a estratégia contrária conduzir a ganhos significativos. Por outro lado, se uma estratégia de momento conduzir a ganhos significativos, então os resultados sugerem uma sub-reação de preços.

\subsection{Adaptação ao mercado brasileiro}

A metodologia a ser aplicada neste estudo difere da metodologia utilizada no trabalho de De Bondt e Thaler (1985) em pelos menos três pontos:

- Número de ativos reduzidos: foram utilizadas somente trinta e oito ações, em função da necessidade de os ativos possuírem liquidez suficiente no período de análise.

- Dados sem distorção inflacionária: foram utilizados os preços dos ativos disponíveis entre julho de 1994 com a implantação do Plano Real até dezembro de 2001.

- Horizonte de tempo reduzido: visando ao aumento do número de observações para avaliações estatisticamente significantes, os retornos foram acumulados semanalmente.

Em cada subperíodo semestral, as ações são classificadas em função do desempenho passado e reunidas em dois tipos de carteiras que concentram ações com retornos acumulados extremos semelhantes: ações com retorno elevado e ações com retorno baixo. O desempenho das carteiras vencedoras e perdedoras é acumulado semanalmente. Diversas carteiras vencedoras e perdedoras serão construídas variando-se o número de ações para possibilitar o estudo de possíveis subreações ou sobre-reações para diferentes níveis de diversificação.

\subsection{Resultados}

A pesquisa teve por objetivo avaliar, a partir da implementação de modelos empíricos baseados em aspectos comportamentais, a existência de sub-reações ou sobre-reações no mercado de capitais brasileiro. Adaptando-se a metodologia de De Bondt e Thaler (1985), os resultados apontam para consistentes sub-reações de mercado quando os retornos não são ajustados pelo nível de risco. Se os excessos de retorno são corrigidos pelo risco, as evidências apontam para a inexistência de estratégias contrárias ou de momento vitoriosas. 
A tabela a seguir apresenta os resultados da aplicação da metodologia descrita, considerando carteiras vencedoras e perdedoras compostas por diferentes números de ativos. As porcentagens representam a diferença entre o excesso de retorno acumulado da carteira perdedora e o excesso de retorno acumulado da carteira vencedora. Desta maneira, uma porcentagem positiva sugere sub-reação e, inversamente, uma porcentagem negativa representa uma sobre-reação. Os tcalculados permitem identificar a significância estatística das diferenças de excesso de retorno entre as carteiras perdedora e vencedora. Os t-críticos para um nível de confiança de 5\% são 1,70 e 1,71, para os casos de retornos calculados sem e com ajuste pelo risco, respectivamente.

Os resultados encontrados mostram uma sub-reação até a terceira semana, seguida de uma sobre-reação que se estende por um número variável de semanas, dependendo da quantidade de ativos nas carteiras e da existência de ajuste em função do risco. A partir da décima-quinta semana todas as situações sugerem uma sub-reação. Por exemplo, para carteiras vencedoras e perdedoras formadas por um único ativo, a estratégia de momento permite, ao final de vinte e duas semanas, um resultado acima do mercado sem correção pelo risco de $26,59 \%$. No mesmo período, para o caso de ajuste pelo risco, a estratégia de momento possibilita um ganho extraordinário de $13,75 \%$.

Porém, as estatísticas t-calculadas mostram fraca significância estatística. Somente para resultados sem ajuste pelo risco e para carteiras formadas por três ativos, obtêm-se diferenças significativas ao nível de 5\%. Exemplificando, após dezoito semanas, a estratégia de momento baseada em carteiras de três ativos garantiria um retorno extraordinário e estatisticamente significante de 13,59\%. Diferenças relevantes ocorrem também para dezesseis e dezenove semanas a partir da formação das carteiras.

Quando se considera o caso de excessos de retornos ajustados pelo risco sistemático em relação ao Ibovespa, apesar de se obter, na maioria dos casos, magnitudes favoráveis à subreação, não se pode rejeitar a hipótese de igualdade de médias. Assim, devido aos baixos tcalculados, as evidências sugerem que, no caso de ajuste pelo nível de risco, oportunidades de ganhos através de estratégias de momento ou estratégias contrárias não levam a ganhos estatisticamente significantes. 


\section{Herbert Kimura}

Tabela: Resultados entre retornos das carteiras vencedoras e das carteiras perdedoras compostas por diferentes números de ativos

\begin{tabular}{|c|c|c|c|c|c|c|c|c|c|c|c|}
\hline \multirow{3}{*}{$\begin{array}{l}\text { Semana } \\
\text { após } \\
\text { formação }\end{array}$} & & \multicolumn{10}{|c|}{$\begin{array}{c}\text { Diferença entre média de excesso de retornos acumulados } \\
\text { Número de ativos }\end{array}$} \\
\hline & & \multicolumn{5}{|c|}{ Sem ajuste pelo nível de risco } & \multicolumn{5}{|c|}{ Com ajuste pelo nível de risco } \\
\hline & & 1 & 2 & 3 & 4 & 5 & T & 2 & 3 & 4 & 5 \\
\hline & $\%$ & 2.91 & 2.19 & 1.23 & 0.71 & -0.19 & 4.36 & 2.23 & 1.42 & 0.79 & 0.10 \\
\hline & $\mathrm{t}$ & 0.76 & 1.04 & 0.80 & 0.53 & -0.14 & 0.94 & 0.70 & 0.70 & 0.53 & 0.08 \\
\hline \multirow[t]{2}{*}{2} & $\%$ & 9.07 & 3.69 & 2.68 & 1.64 & 0.37 & 7.96 & 3.15 & 2.71 & 1.04 & 0.67 \\
\hline & $\mathrm{t}$ & 1.64 & 1.12 & 1.22 & 0.94 & 0.22 & 1.15 & 0.78 & 0.94 & 0.47 & 0.32 \\
\hline \multirow[t]{2}{*}{$\overline{3}$} & $\%$ & 8.50 & 3.57 & 3.80 & 2.78 & 1.07 & 8.88 & 2.73 & 3.24 & 1.91 & 1.19 \\
\hline & $\mathrm{t}$ & 1.22 & 0.92 & 1.48 & 1.33 & 0.53 & 1.01 & 0.51 & 0.86 & 0.65 & 0.45 \\
\hline \multirow[t]{2}{*}{$\overline{4}$} & $\%$ & -2.15 & -1.34 & -0.61 & -0.95 & -2.62 & 0.45 & -3.46 & -1.93 & -2.70 & -2.61 \\
\hline & $\mathrm{t}$ & -0.21 & -0.22 & -0.15 & -0.30 & -0.92 & 0.04 & -0.48 & -0.39 & -0.69 & -0.80 \\
\hline \multirow[t]{2}{*}{$\overline{5}$} & $\%$ & -2.14 & -2.49 & -1.28 & -1.29 & -2.50 & 4.37 & -1.64 & -0.99 & -1.94 & -2.45 \\
\hline & $\mathrm{t}$ & -0.18 & -0.39 & -0.31 & -0.38 & -0.83 & 0.30 & -0.20 & -0.18 & -0.44 & -0.65 \\
\hline \multirow[t]{2}{*}{6} & $\%$ & 2.11 & 0.12 & 0.92 & 0.20 & -1.33 & 9.28 & -0.19 & 0.63 & -0.39 & -0.91 \\
\hline & $\mathrm{t}$ & 0.18 & 0.02 & 0.20 & 0.05 & -0.40 & 0.65 & -0.02 & 0.10 & -0.08 & -0.22 \\
\hline \multirow[t]{2}{*}{7} & $\%$ & 1.96 & -2.13 & -1.62 & -2.82 & -3.47 & 5.06 & -1.18 & -0.78 & -2.35 & -2.79 \\
\hline & $\mathrm{t}$ & 0.17 & -0.31 & -0.35 & -0.67 & -0.90 & 0.33 & -0.13 & -0.11 & -0.40 & -0.50 \\
\hline \multirow[t]{2}{*}{$\overline{8}$} & $\%$ & 4.61 & -0.48 & 0.67 & -1.73 & -2.50 & 12.28 & 1.90 & -0.19 & -1.52 & -1.88 \\
\hline & $\mathrm{t}$ & 0.30 & -0.06 & 0.11 & -0.34 & -0.55 & 0.66 & 0.18 & -0.02 & -0.23 & -0.32 \\
\hline \multirow[t]{2}{*}{9} & $\%$ & 6.70 & 0.93 & 0.67 & -1.52 & -2.67 & 11.81 & 3.50 & -0.44 & -2.97 & -3.09 \\
\hline & $\mathrm{t}$ & 0.45 & 0.11 & 0.12 & -0.31 & -0.60 & 0.64 & 0.32 & -0.06 & -0.44 & -0.51 \\
\hline \multirow[t]{2}{*}{10} & $\%$ & 8.47 & 1.74 & 1.37 & -1.13 & -1.96 & 13.47 & 4.15 & 0.34 & -2.52 & -2.38 \\
\hline & $\mathrm{t}$ & 0.60 & 0.22 & 0.25 & -0.24 & -0.46 & 0.75 & 0.40 & 0.04 & -0.39 & -0.41 \\
\hline \multirow[t]{2}{*}{11} & $\%$ & 7.51 & 1.53 & 0.76 & -0.61 & -2.18 & 14.27 & 3.42 & 0.54 & -2.15 & -2.14 \\
\hline & $\mathrm{t}$ & 0.51 & 0.18 & 0.14 & -0.12 & -0.51 & 0.75 & 0.29 & 0.07 & -0.32 & -0.35 \\
\hline \multirow[t]{2}{*}{12} & $\%$ & 8.11 & 2.53 & 1.98 & 0.15 & -1.06 & 17.92 & 6.14 & 1.82 & -0.41 & -1.08 \\
\hline & $\mathrm{t}$ & 0.54 & 0.29 & 0.34 & 0.03 & -0.24 & 0.89 & 0.49 & 0.21 & -0.06 & -0.16 \\
\hline \multirow[t]{2}{*}{13} & $\%$ & 9.52 & 4.33 & 3.88 & 1.47 & -0.77 & 18.00 & 6.07 & 2.04 & -0.08 & -1.18 \\
\hline & $\mathrm{t}$ & 0.64 & 0.49 & 0.66 & 0.28 & -0.17 & 0.91 & 0.48 & 0.22 & -0.01 & -0.17 \\
\hline \multirow[t]{2}{*}{14} & $\%$ & 15.46 & 7.38 & 6.37 & 2.48 & 0.08 & 22.50 & 7.23 & 3.03 & 0.75 & -0.41 \\
\hline & $\mathrm{t}$ & 0.90 & 0.74 & 0.97 & 0.45 & 0.02 & 1.13 & 0.59 & 0.35 & 0.10 & -0.06 \\
\hline 15 & $\%$ & 18.58 & 10.09 & 8.77 & 4.84 & 1.92 & 23.43 & 9.95 & 6.01 & 2.82 & 2.20 \\
\hline & $\mathrm{t}$ & 1.05 & 1.01 & 1.35 & 0.89 & 0.42 & 1.09 & 0.78 & 0.66 & 0.38 & 0.32 \\
\hline 16 & $\%$ & 20.83 & 11.82 & 11.73 & 8.48 & 5.38 & 26.68 & 11.04 & 9.08 & 5.52 & 4.42 \\
\hline & $\mathrm{t}$ & 1.12 & 1.16 & 1.81 & 1.63 & 1.24 & 1.23 & 0.86 & 1.00 & 0.76 & 0.66 \\
\hline 17 & $\%$ & 19.14 & 11.83 & 11.41 & 7.72 & 4.71 & 24.82 & 12.68 & 9.82 & 4.87 & 3.89 \\
\hline & $\mathrm{t}$ & 1.01 & 1.12 & 1.69 & 1.42 & 1.04 & 1.11 & 0.95 & 1.05 & 0.65 & 0.56 \\
\hline 18 & $\%$ & 22.85 & 13.52 & 13.59 & 8.22 & 5.75 & 24.38 & 12.91 & 10.75 & 6.13 & 5.21 \\
\hline & $\mathrm{t}$ & 1.17 & 1.25 & 1.94 & 1.46 & 1.22 & 1.06 & 0.94 & 1.08 & 0.76 & 0.71 \\
\hline 19 & $\%$ & 24.81 & 12.98 & 13.36 & 8.25 & 5.83 & 22.33 & 13.90 & 12.48 & 7.58 & 6.58 \\
\hline & $\mathrm{t}$ & 1.24 & 1.13 & 1.81 & 1.41 & 1.20 & 0.94 & 0.99 & 1.26 & 0.96 & 0.91 \\
\hline 20 & $\%$ & 25.88 & 11.09 & 10.99 & 6.80 & 5.03 & 17.10 & 11.36 & 10.16 & 5.87 & 5.99 \\
\hline & $\mathrm{t}$ & 1.30 & 0.91 & 1.40 & 1.10 & 0.98 & 0.67 & 0.76 & 0.96 & 0.71 & 0.80 \\
\hline 21 & $\%$ & 26.34 & 11.98 & 11.09 & 6.51 & 4.65 & 16.42 & 10.58 & 7.70 & 3.80 & 4.75 \\
\hline & $\mathrm{t}$ & 1.30 & 0.98 & 1.42 & 1.01 & 0.87 & 0.63 & 0.70 & 0.71 & 0.46 & 0.63 \\
\hline 22 & $\%$ & 26.59 & 11.45 & 10.87 & 6.49 & 4.96 & 13.73 & 9.22 & 7.68 & 3.87 & 5.44 \\
\hline & $\mathrm{t}$ & 1.26 & 0.88 & 1.31 & 0.98 & 0.90 & 0.49 & 0.57 & 0.67 & 0.44 & 0.68 \\
\hline 23 & $\%$ & 25.88 & 12.29 & 12.53 & 6.88 & 4.48 & 15.76 & 11.23 & 9.65 & 4.73 & 5.78 \\
\hline & $\mathrm{t}$ & 1.24 & 1.00 & 1.56 & 1.08 & 0.82 & 0.59 & 0.74 & 0.91 & 0.57 & 0.77 \\
\hline 24 & $\%$ & 22.31 & 9.76 & 10.59 & 4.76 & 2.02 & 10.95 & 9.08 & 7.24 & 2.15 & 3.83 \\
\hline & 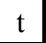 & 1.05 & 0.79 & 1.31 & 0.75 & 0.37 & 0.41 & 0.59 & 0.67 & 0.26 & 0.51 \\
\hline
\end{tabular}




\section{COMENTÁRIOS FINAIS}

O estudo de sobre-reações ou sub-reações permite identificar se fatores comportamentais dos investidores podem influenciar, de modo irracional, os preços dos ativos financeiros. Tendo em vista a crescente importância das técnicas de finanças comportamentais, este artigo buscou apresentar resultados da aplicação de uma metodologia para identificar oportunidades de ganhos através da exploração de estratégias contrárias e de momento.

Apesar das diferenças entre excessos de retorno entre carteiras perdedoras e vencedoras apontarem para uma sub-reação de curto e médio prazo, intercalada por um período breve de sobre-reação, a maioria dos resultados não é estatisticamente significante. Para o caso de retornos calculados sem ajuste pelo risco, observa-se que cerca de dezesseis semanas após a formação da estratégia de momento, os ganhos são relevantes. Porém, quando se ajusta os retornos pelo nível de risco, nenhum resultado permite rejeitar a hipótese de diferença nula entre excessos de retornos acumulados de carteiras perdedoras e vencedoras. Desta forma, o estudo proporciona evidências de que os aspectos comportamentais têm uma influência marginal sobre os preços das ações do mercado brasileiro. Neste contexto, pode-se sugerir que o excesso de confiança, o conservadorismo exagerado e outros vieses de julgamento dos investidores não chegam a limitar consideravelmente a eficiência do mercado e os ajustes através do processo de arbitragem.

Obviamente, considerando as restrições do estudo, no que diz respeito à pequena amostra de ações, ao horizonte de tempo reduzido e à limitação do número de observações de retornos, é importante que diversas outras investigações sejam realizadas para um melhor entendimento de possíveis direcionadores dos preços das ações. Assim, o desenvolvimento de novos modelos e técnicas de finanças comportamentais pode motivar outros estudos sobre aspectos psicológicos que afetam o mercado.

\section{Bibliografia}

BALL, R.; KOTHARI, S. P. Nonstationary expected returns: implications for tests of market efficiency and serial correlation in returns. Journal of Financial Economics, v.25, p.51-74, 1989.

BARBERIS, N.; SHLEIFER, A.; VISHNY, R. A model of investor sentiment. Journal of Financial Economics, v.49, n.3, p.307-343, 1998.

BASU, S. Investment performance of common stocks in relation to their price-earnings ratios: a test of the efficient market hypothesis. Journal of Finance, v.3, p.663-682, 1977.

BURR, B.B. Behavioral finance: more light shining on the whys of investing. Pensions \& Investment, pp. 32-34. May 26, 1997.

CHAN, L. K. C.; JEGADEESH, N.; LAKONISHOK, J. Momentum strategies. Journal of Finance, v.51, n.1, p.1681-1713, 1996 
CONRAD, J.; KAUL, G. An anatomy of trading strategies. Review of Financial Studies, v.11, p.489-519, 1998.

DANIEL, K.; HIRSHLEIFER, D; SUBRAHMANYAM, A. Investor psychology and security market under and overreactions. Journal of Finance, v.53, n.6, p.1839-1886, 1998.

DE BONDT, W. F. M.; THALER, R. H. Does the stock market overreact? Journal of Finance, v.40, n.3, p.793-807, 1985.

DE BONDT, W. F. M.; THALER, R. H. Further evidence on investor overreaction and stock market seasonality. Journal of Finance, v.42, n.3, p.793-807, 1987.

EDWARDS, W. Conservatism in human information processing. In: KLEINMUNTZ, B. Formal Representation of Human Judgment. New York, Wiley, 1968.

HONG, H.; STEIN, J. C. A unified theory of underreaction, momentum trading, and overreaction in asset markets. Journal of Finance, v.54, n.6, p.2143-2184, 1999.

JEGADEESH, N.; TITMAN, S. Returns to buying winners and selling losers: implications for stock market efficiency. Journal of Finance, v.48, p.65-91, 1993.

KAHNEMAN, D.; TVERSKY, A. Prospect theory: an analysis of decision under risk. Econometrica, p.263-291, March, 1979

LEVY, R. Relative Strength as a Criterion for Investment Strategies. Journal of Finance, v.22, p.595-610, 1967.

MUN, J.; VASCONCELlOS, G. M.; KISH, R. The contrarian / overreaction hypothesis: an analysis of the U.S. and Canadian stock markets. Global Finance Journal, v.11, n.1, 2000.

PLOUS, S. The psychology of judgment and decision making. McGraw-Hill, 1993.

SHEFRIN, H. M. Beyond greed and fear. Harvard Business School Press, 2000.

SHLEIFER, A. Inefficient markets: an introduction to behavioral finance. New York, Oxford University Press, 2000.

SLOVIC, P. Psychological study of human judgment: implications for investment decision making. Journal of Finance, v.27, p.779-801, 1972.

ZAROWIN, P. Size, seasonality, and stock market overreaction. Journal of Financial and Quantitative Analysis, v.25, p.113-125, 1990. 